PESQUISA

\title{
BIOPROSPECÇÃO DE ANTIBIÓTICOS PRODUZIDOS POR FUNGOS DA CAATINGA
}

\author{
Clementino LC ${ }^{*}$, Barbosa $\mathrm{CC}^{* *}$, Silva DPD ${ }^{* * *}$, Silva FD ${ }^{* * *}$, Queiroz $\mathrm{JCF}^{* * * *}$
}

Resumo

O desenvolvimento de novos antibióticos está atrelado ao desafio de combater microrganismos super-resistentes, bem como possuir amplo espectro de ação. Para atingir essa meta, várias fontes de obtenção são pesquisadas nos mais diversos ambientes. Nesse sentido, este trabalho buscou a utilização de fungos filamentosos coletados no Bioma Caatinga na microrregião do Cariri paraibano para a produção de antibióticos, considerando-se a importância de pesquisas nesse sentido, utilizando fungos dessa região, abrindo expectativa de inovação na indústria farmacêutica. As amostras fúngicas foram coletadas e avaliadas quanto ao seu potencial em produzir compostos antimicrobianos contra linhagens patogêncas de Escherichia coli (ATCC 25922) e Staphylococcus aureus (ATCC 25923). Entre os 72 isolados avaliados, $57(79,17 \%)$ apresentaram alguma atividade antimicrobiana, dos quais $27(47,37 \%)$ possuíram atividade contra ambas as bactérias, e $30(52,63 \%)$ com atividade contra apenas uma delas. Nos testes antibiograma, foram selecionados os isolados CDSA30 e CDSA71 para a purificação dos extratos antibacterianos por meio de CLAE-FR. Na purificação dos extratos antimicrobianos, foram encontradas duas substâncias que apresentaram atividade antibiótica contra

\footnotetext{
* Mestrando em Engenharia Química pela Universidade Federal de São Carlos; Graduado em Engenharia de Biotecnologia e Bioprocessos pela Universidade Federal de Campina Grande; Professor na Universidade Federal de São Carlos, Centro de Ciências Exatas e de Tecnologia; Rodovia Washington Luís, Km 235, s/n, Jardim Guanabara, 13565905, São Carlos, São Paulo, Brasil; leandrocclementino@hotmail.com ** Graduanda de Engenharia de Produção no Centro Universitário UNA de Aimorés; mila.casbar@gmail.com

*** Graduada em Engenharia de Biotecnologia e Bioprocessos pela Universidade Federal de Campina Grande; daysepdias@hotmail.com ${ }^{* * * *}$ Graduando de Engenharia de Biotecnologia e Bioprocessos pela Universidade Federal de Campina Grande; felipedouglasichigo@gmail.com ${ }^{* * * * *}$ Pós-doutor e Doutor em Biotecnologia pela Universidade de São Paulo; Professor da Universidade Federal de Campina Grande; queiroz.jcf@gmail.com
} 
as duas cepas bacterianas utilizadas; esses fungos foram identificados como pertencentes ao gênero Aspergillus. O estudo do efeito da temperatura sobre a produção de antibióticos mostrou que há maior rendimento na produção de metabólitos com atividade antimicrobiana quando a temperatura de cultivo for a $45^{\circ} \mathrm{C}$.

Palavras-chave: Metabólitos secundários. Biotecnologia. Purificação. Antibiograma.

\title{
Bioprospection of antibiotics produced by caatinga fungi
}

\begin{abstract}
The development of new antibiotics is linked to the challenge of fighting super-resistant microorganisms, as well as owning broad spectrum of action. To achieve this goal, several sources of obtaining are researched in many different environments. Therefore, this study aimed to use filamentous fungi collected at Caatinga, in the Cariri micro-region, for the production of antibiotics, by means of the importance of researches in this sense using fungi of the region, opening expectation of pharmaceutical industry innovation. The fungal samples were collected, and evaluated for their potential to produce antimicrobial compounds against pathogenic strains of Escherichia coli (ATCC 25922) and Staphylococcus aureus (ATCC 25923) bacteria. Among the 72 isolates, 57 (79.17\%) had some antimicrobial activity, of which 27 (47.37\%) possessed activity against both bacteria, and 30 (52.63\%) with activity against only one of them. After antibiotic susceptibility tests, the CDSA30 and CDSA71 isolates were selected for purification of antibacterial extracts by RP-HPLC. In the purification of antimicrobial extracts, were found two substances with antibiotic activity against both bacterial strains used. These fungi were identified as belonging to Aspergillus genus. The study of the effect of temperature on the antibiotics production showed that there is increased yield of metabolites production with antimicrobial activity when the fermentation temperature is $45^{\circ} \mathrm{C}$.
\end{abstract}

Keywords: Secondary metabolites. Biotechnology. Purification. Antibiogram.

\section{INTRODUÇÃO}

Os produtos naturais sempre estiveram ligados à humanidade; desde os tempos remotos o homem busca a cura dos males de acordo com o etnoconhecimento disponível sobre plantas e outros produtos naturais. ${ }^{1}$ Vários medicamentos foram e são desenvolvidos a partir de substâncias encontradas na natureza nos mais diversos ambientes, como a Antracimicina, potente antibiótico contra o bacilo Anthrax, isolada de um Actinomiceto marinho. ${ }^{2}$ Ao passar dos anos, a biotecnologia aliou-se à indústria farmacêutica para impulsionar e otimizar a descoberta e o aprimoramento de novos fármacos.

As pesquisas que envolvem novos antibióticos se justificam por vários fatores, o aparecimento de novos patógenos e a seleção de microrganismos resistentes, diferentes efeitos colaterais dos 
antibióticos existentes, necessidade de identificação de antibióticos para a agricultura que poderão substituir os agrotóxicos e a resistência adquirida pelos microrganismos patogênicos aos antibióticos existentes. $^{3}$

Entre os fatores citados, a resistência desenvolvida por microrganismos patogênicos é um dos mais preocupantes; essa problemática traz um grande desafio para os novos antibióticos. Estima-se que 90 a 95\% das linhagens de Staphylococcus aureus existentes no mundo são resistentes à penicilina, e em países da Ásia 70 a 80\% dessas linhagens são meticilina resistentes. ${ }^{4}$

Entre os microrganismos com perspectiva para o desenvolvimento de novos antibióticos mais eficazes ou superiores aos existentes, com intermédio da biotecnologia e utilizando fontes naturais renováveis, uma fonte amplamente pesquisada para esse fim são os fungos. De acordo com Santos, ${ }^{5}$ os fungos são conhecidos por seu papel ambiental, por sua versatilidade na obtenção de metabólitos secundários e pela facilidade na reprodutibilidade de resultados.

Vários compostos com atividade antibiótica, que vão desde antiparasitários, antifúngicos e antibióticos até anticâncer, já foram produzidos, isolados e caracterizados a partir de fungos. ${ }^{6,75}$

No Brasil alguns grupos de pesquisa já conseguiram purificar e caracterizar quimicamente alguns compostos com atividade antibacteriana de fungos endofíticos ou micorrízicos e de diversos biomas, como na Amazônia e no Cerrado, por exemplo. ${ }^{7}$

No bioma Caatinga, essa linha de pesquisa é bastante pontual. Esse bioma está localizado na região Semiárida brasileira, em sua maioria na porção Nordeste do país, ocupando $9.000 \mathrm{Km}^{2}$, cerca de $8 \%$ do território nacional. ${ }^{8} \mathrm{O}$ clima semiárido submete sua biota a condições extremas, como temperaturas médias anuais entre $26 \mathrm{e} 28^{\circ} \mathrm{C}$, chegando acima dos $35^{\circ} \mathrm{C}$ em alguns períodos do ano e baixas precipitações que variam de 300 a 1000 mm anuais, que são irregulares e concentradas de três a seis meses por ano. ${ }^{9}$

Esta pesquisa, embora preliminar, mostra o potencial que a microbiota fúngica da Caatinga na região do Cariri paraibano, Semiárido brasileiro, possui em gerar novos antibióticos para a indústria farmacêutica, explorando fontes naturais renováveis, de simples manuseio e com grande potencial não apenas para a produção de antibióticos, mas para outros fins a partir da Coleção de Fungos desenvolvida com microrganismos exclusivos do Bioma Caatinga.

\section{MATERIAIS E MÉTODOS}

\subsection{CONSTRUÇÃO DA BIBLIOTECA DE FUNGOS}

A metodologia descrita foi conduzida no Laboratório de Química e Laboratório de Biotecnologia do Centro de Desenvolvimento Sustentável do Semiárido (CDSA), da Universidade Federal de Campina Grande (UFCG). 


\subsubsection{Coleta das amostras}

Foram realizadas coletas simples e aleatórias semanais, no período de setembro a outubro de 2011, nas mediações do CDSA (Sumé/Paraíba) (740’19” S, 3652’ 48” W). As amostras, cerca de $2 \mathrm{~g}$ cada, foram retiradas da camada superficial do solo e de partes aéreas (folhas) de plantas arbusculares, com o auxílio de uma espátula, e inseridas separadamente em tubo cônico esterilizado de 2,0 mL.

\subsubsection{Processamento das amostras}

Imediatamente após a coleta, as amostras seguiram para o laboratório onde foi adicionado $1 \mathrm{~mL}$ de solução salina $0,9 \%$ nos tubos e agitado por 20 segundos, todo o sobrenadante formado foi retirado, inserido em placas de Petri contendo meio BSA, $100 \mathrm{~g} / \mathrm{L}$ de Batata, $20 \mathrm{~g} / \mathrm{L}$ de Sacarose e $5 \mathrm{~g} / \mathrm{L}$ de Ágar, com pH 6,0, e incubados em Câmara BOD a $37^{\circ} \mathrm{C}$ e observado o crescimento fúngico em 24 e 48 horas.

\subsubsection{Isolamento e armazenagem dos fungos}

Após observar o crescimento em placa, foram selecionados os fungos que apresentaram maior crescimento em relação aos demais, estes foram repicados em meio BSA e incubados por 24 horas em Câmara BOD, a $37^{\circ} \mathrm{C}$. Após essa etapa, os isolados foram inoculados em frascos de xarope âmbar contendo $10 \mathrm{~mL}$ de meio BSA, incubados em câmara $\mathrm{BOD}$, a $37^{\circ} \mathrm{C}$, por 48 horas, em seguida, foram armazenados em refrigerador a $8{ }^{\circ} \mathrm{C}$, e nomeados de "CDSA" seguido do número na ordem de armazenagem, formando, assim, a Coleção de Fungos da Caatinga do CDSA.

\subsection{OBTENÇÃO DOS METABÓLITOS BIOATIVOS}

Todos os isolados foram submetidos ao crescimento em meio complexo semissólido, incubados por 144 horas, a $37^{\circ} \mathrm{C}$, em Câmara BOD. O meio constituía-se de $5 \mathrm{~g}$ de aveia comercial em flocos homogeneizada em $15 \mathrm{~mL}$ de água destilada, autoclavado durante 30 minutos. Após o término da fermentação, foram adicionados, em cada frasco de cultura, $10 \mathrm{~mL}$ de clorofórmio PA (99,8\%), homogeneizado e filtrado em papel de filtro $(28 \mu \mathrm{m})$. Em seguida, os extratos obtidos foram filtrados a vácuo e armazenados em tubos plásticos sob refrigeração.

Realizou-se também o cultivo dos isolados em meio líquido constituído de $10 \mathrm{~g} / \mathrm{L}$ de Extrato de Malte (Himedia ${ }^{\circ}$ e $18 \mathrm{~g} / \mathrm{L}$ de Dextrose, com pH 7,0, distribuídos em Erlenmeyers e cultivados em agitador rotativo, a $37{ }^{\circ} \mathrm{C}$, por 72 horas, sob agitação de $140 \mathrm{rpm}$. Na extração dos metabólitos obtidos via fermentação em meio líquido, foi adicionado ao caldo fermentado $10 \mathrm{~mL}$ de clorofórmio 
PA $(99,8 \%)$, homogeneizado e filtrado em papel de filtro $(28 \mu \mathrm{m})$, formando três fases denominadas A, B e C, que foram separadas em funil de separação, concentradas em rotoevaporador e armazenadas em tubos plásticos sob refrigeração.

\subsection{ENSAIO DA ATIVIDADE ANTIMICROBIANA}

\subsubsection{Microrganismos indicadores da atividade antibacteriana}

Foram utilizados microrganismos patogênicos a humanos e animais como indicadores da atividade antibiótica dos extratos de fungos obtidos. Foram utilizadas as cepas de Staphylococcus aureus ATCC 25923 e Escherichia coli ATCC 25922. As cepas bacterianas foram gentilmente cedidas pelo Prof. José Pinto de Siqueira Júnior, Departamento de Biologia Molecular (UFPB), conservadas em meio de cultura Infusão de Cérebro-Coração em Ágar (BHIA). O inóculo bacteriano foi padronizado por meio de diluição seriada, utilizando uma concentração de 9x105 UFC/mL em cada placa do teste antibiograma.

\subsubsection{Preparo dos discos de papel}

Os discos de papel foram preparados de acordo com a Farmacopéia Brasileira ${ }^{10}$ com algumas adaptações. Foi adicionado em cada disco de papel de filtro de $13 \mathrm{~mm}, 10 \mu \mathrm{L}$ do extrato obtido de cada isolado, esperando a absorção e repetindo o processo novamente. A fim de comparar o potencial antibacteriano dos metabólitos produzidos, foram preparados discos contendo o antibiótico amoxicilina $100 \mathrm{mg} / \mathrm{mL}$, como controle positivo e discos contendo apenas clorofórmio PA (99,8\%), como controle negativo.

\subsubsection{Teste antibiograma}

Semeou-se $1 \mathrm{~mL}$ da solução padrão de bactérias $S$. aureus e E. coli em placas de Petri contendo meio de cultura ADCM composto de 32,5 g/L de Ágar-caseína, 20 g/L de Dextrose e 10 g/L de Extrato de Malte, com pH 7,0, aguardando secar. Após essa etapa, os discos contendo os extratos foram dispostos sobre as bactérias na quantidade de três por placa, mais um disco contendo amoxicilina e um contendo clorofórmio e incubados em Câmara BOD a $37^{\circ} \mathrm{C}$ por 12 horas.

A atividade antibiótica dos extratos foi medida por intermédio do halo de inibição do crescimento bacteriano com o auxílio de uma régua milimetrada e comparada com o controle positivo. Foi considerada atividade antibacteriana os extratos que conseguiram inibir totalmente ou 
parcialmente o crescimento bacteriano. Os testes antibiograma foram realizados em duplicada para cada cepa de microrganismo teste.

\subsection{EFEITO DA TEMPERATURA NA PRODUÇÃO DOS ANTIBIÓTICOS}

Foram selecionados os melhores produtores de biomoléculas antibióticas; estes foram cultivados em meio BSA por 72 horas, em triplicata. Para uniformização do inóculo fúngico, adicionouse $6 \mathrm{~mL}$ de solução salina $(0,9 \%)$ e uma gota de detergente em cada placa, a fim de obter-se uma solução homogênea de esporos. Foi inoculado $1 \mathrm{~mL}$ da suspensão de esporos em meio semissólido de aveia, cultivado por 144 horas, em 5 repetições, nas temperaturas de $28^{\circ} \mathrm{C}, 37^{\circ} \mathrm{C}$ e $45^{\circ} \mathrm{C}$. Em seguida, extraíram-se os metabólitos produzidos conforme metodologia e obtenção dos extratos descrita anteriormente, e, em seguida, realizaram-se os testes antibiograma.

Os dados obtidos foram submetidos a uma análise no software Origin Pro 8, utilizando o teste de Fisher, que é um teste não paramétrico, útil para analisar dados discretos (nominais ou ordinais), quando os tamanhos das amostras são pequenos, e funciona atribuindo a cada indivíduo do grupo um entre dois escores possíveis. ${ }^{11}$

\subsection{PURIFICAÇÃO DOS EXTRATOS POR CLAE}

A Cromatografia Líquida de Alta Eficiência foi realizada utilizando-se uma coluna de Fase Reversa (CLAE-FR) e conduzida no Laboratório de Caracterização de Biomoléculas CCEN (UFPB), em colaboração com o Prof. Josean Fechine e a Doutoranda Camila Holanda de Albuquerque.

As amostras provenientes dos extratos em clorofórmio dos isolados com melhor produção de biomoléculas antibióticas foram secas em calor seco, em seguida, diluídas em Metanol a 50\% e filtradas em filtro com poro de 0,45 $\mu \mathrm{m}$. Foi utilizada uma coluna C18 (150 mm X 4,6 mm, com partícula de $5 \mu \mathrm{m}$ ) ShimPack - Shimadzu, em um cromatógrafo Shimadzu, Modelo Série 10A vp.

Foi programado um gradiente de água deionizada (Tampão A) e Metanol (Tampão B), a um fluxo de $1 \mathrm{~mL} / \mathrm{min}$, em que foi passado um volume de Coluna (5 minutos) em 5\% de metanol. O gradiente de Metanol foi crescente até 95\% de metanol, em 30 minutos, seguido de uma lavagem da coluna com $95 \%$ de metanol por 5 minutos. Os cromatogramas apresentados neste trabalho foram realizados com leitura do eluído em $289 \mathrm{~nm}$.

\subsection{IDENTIFICAÇÃO DOS ISOLADOS}

Foi utilizada a técnica de microcultivo, conforme descrito pela Anvisa ${ }^{12}$ com adaptações. Foi utilizado o meio batata-dextrose-ágar (BDA), os fungos foram incubados a $37{ }^{\circ} \mathrm{C}$ com acompanhamento do crescimento por 96 horas e comparação das imagens microscópicas obtidas com literatura especializada. 


\section{RESULTADOS E DISCUSSÃO}

\subsection{COLEÇÃO DE FUNGOS DA CAATINGA}

Após várias coletas de solo e partes aéreas de plantas e cultivo do material obtido em meio BSA, observou-se uma grande variedade de espécimes fúngicas. Ocorreu perda de algumas colônias em decorrência da contaminação por bactérias; preferiu-se a não utilização de antibióticos visto que a presença destes no meio de cultura poderia ocasionar o mascaramento do potencial dos fungos para a produção de antibióticos. No entanto foi possível a obtenção de 72 isolados fúngicos, por seleção de colônias puras. A Figura 2 mostra colônias purificadas e colônias nos tubos âmbar para serem armazenadas sob refrigeração. Estas estão sendo utilizadas para testes de produção de antibióticos, assim como outras pesquisas no Centro de Desenvolvimento Sustentável do Semiárido.

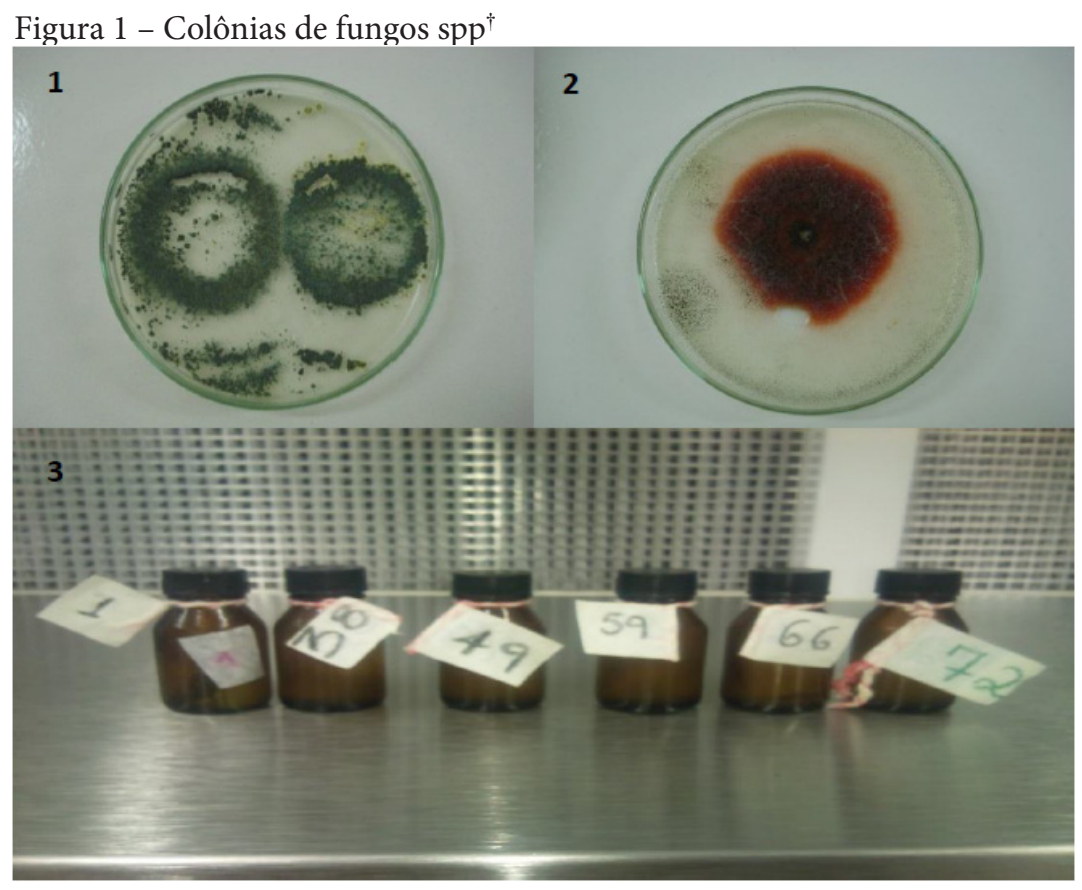

Fonte: os autores.

Conseguinte a construção da Coleção de Fungos, partiu-se para o cultivo em meio semissólido de aveia, meio este que proporcionou a produção dos metabólitos secundários responsáveis pela atividade antibiótica. Um meio de cultura contendo apenas um nutriente, ou poucos nutrientes, nesse caso a aveia, induz o fungo a produzir substâncias de defesa para vencer a competição por alimento. Geralmente esse fato é evidenciado pela esporulação e, consequentemente, pela cor peculiar que o fungo obtém no meio de aveia. ${ }^{12}$

\footnotetext{
† Colônias de fungos filamentosos após isolamento (1 e 2). Fungos armazenados em vidro âmbar, formando a Seleção de Fungos do Semiárido (3).
} 
Calvo et al. ${ }^{12}$ e Okafor ${ }^{14}$ levantam a hipótese de que a produção desses metabólitos secundários regula algumas mudanças morfológicas para os microrganismos, envolvidas comumente com a esporulação, ativando-a ou produzindo pigmentos para suas estruturas.

Na Figura 3, torna-se evidente a esporulação excessiva e a cor característica de cada fungo após cultivo em meio semissólido de aveia, podendo atrelar a esse fato que os fungos que apresentaram essa mudança morfofisiológica produziram metabólitos secundários, testados posteriormente quanto ao seu potencial antibiótico.
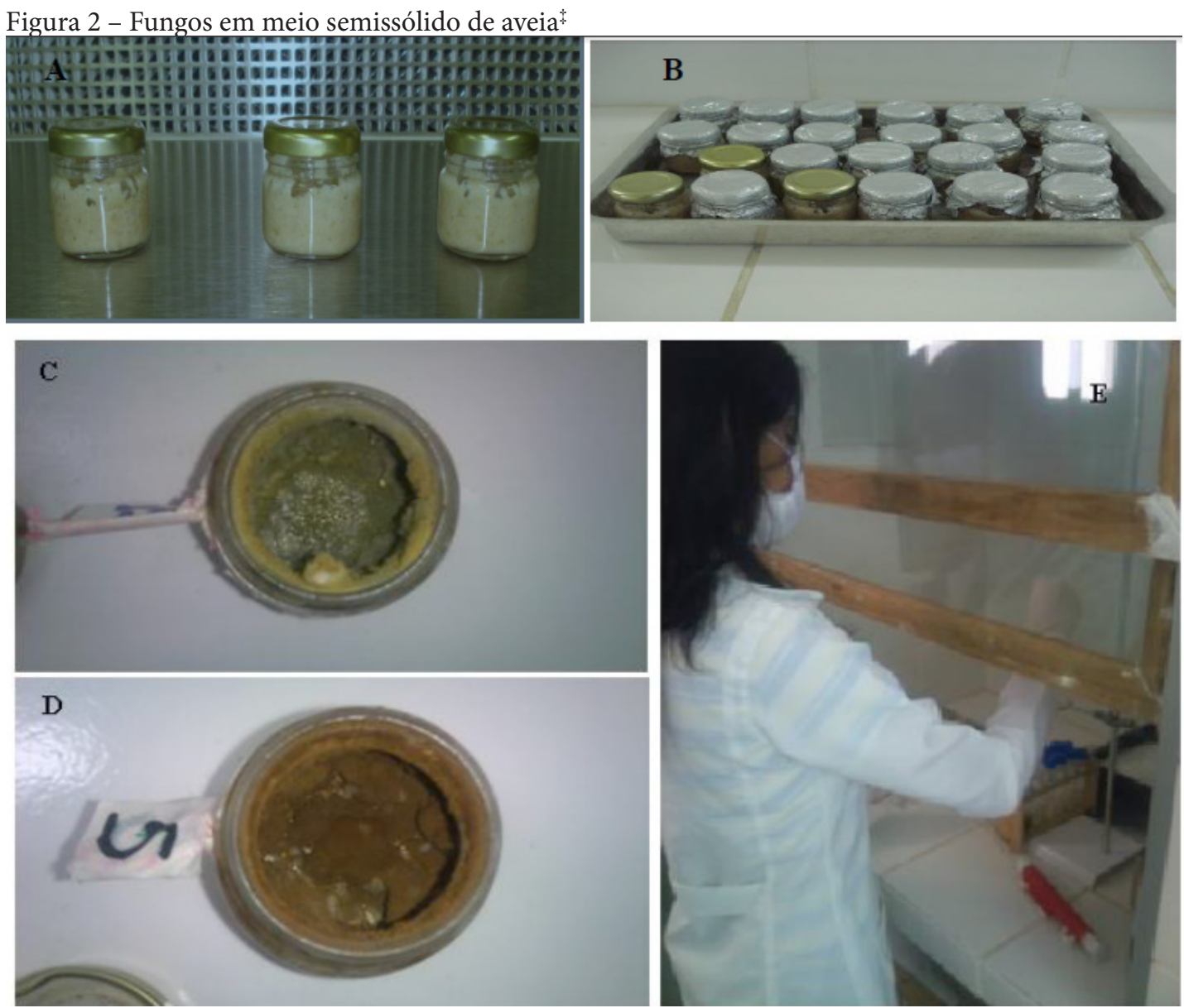

Fonte: os autores.

Entre os 72 isolados da Coleção de Fungos da Caatinga, 57 (79\%) apresentaram atividade antimicrobiana comprovada por meio dos testes de atividade antibacteriana em meio ADCM, dos quais 27 extratos $(47,37 \%)$ obtidos dos isolados apresentaram atividade contra E. coli e S. aureus e 30 extratos $(52,63 \%)$ com atividade apenas contra uma dessas bactérias.

O Gráfico 1 apresenta de forma clara a atividade antibacteriana dos extratos fúngicos. Nota-se que quatro extratos apresentaram atividade contra E. coli, bactéria Gram negativa responsável por um grande número de infecções, descrita como uma das mais antigas bactérias simbiontes do homem, ${ }^{15}$

* Frascos de vidro com tampa de metal (autoclavável), volume de $40 \mathrm{~mL}$, contendo meio semissólido de aveia (A e B). Aspecto dos fungos após o cultivo em meio semissólido de aveia (C e D). Procedimento de extração dos metabólitos secundários em capela de exaustão (E). 
26 extratos inibiram total ou parcialmente o crescimento de $S$. aureus, bactéria Gram positiva que coloniza principalmente as vias nasais de humanos e é responsável por inúmeras infecções purulentas; essa bactéria está associada a intoxicações alimentares e à síndrome do choque tóxico. ${ }^{15}$

Este resultado é instigante, visto que aproximadamente $80 \%$ dos isolados testados apresentaram atividade antibiótica, estes resultados são superiores aos observados por Bachiega et al., ${ }^{16}$ que analisou várias espécies fúngicas da região de Araraquara - Brasil, em que 53,1\% apresentaram atividade antimicrobiana, quando cultivados em meio pobre de nutrientes.

Figura 3 - Quantidade de extratos e atividade antibiótica confirmada para os microrganismos teste

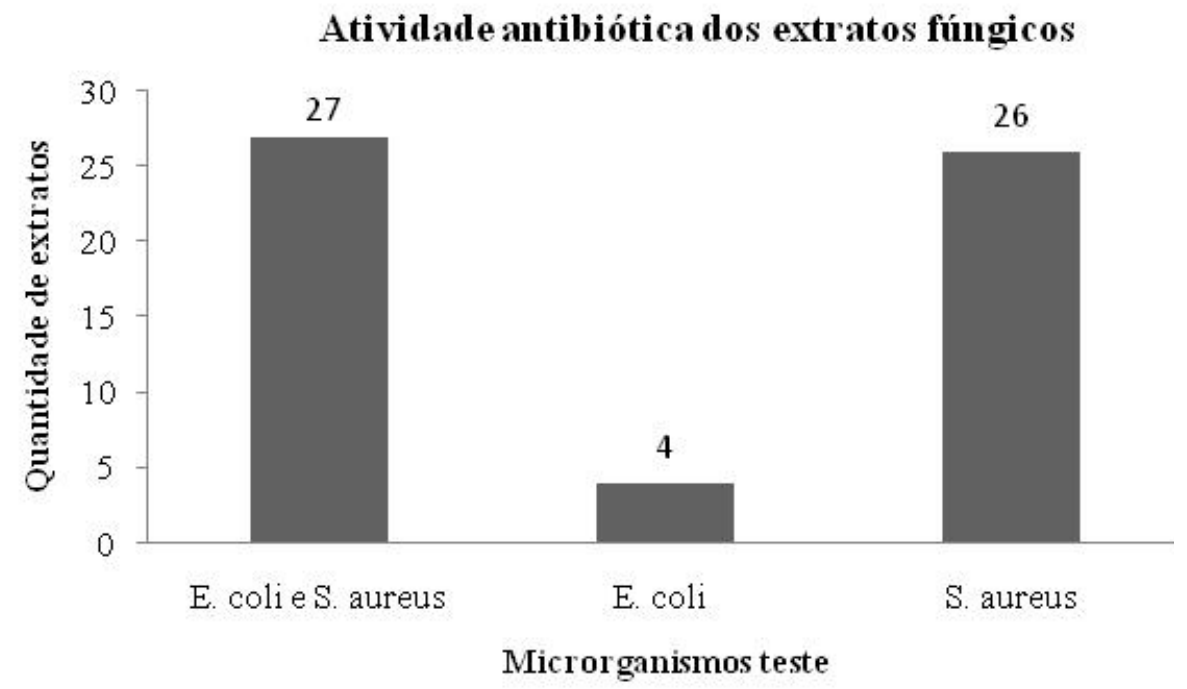

Fonte: os autores.

Os dados métricos dos antibiogramas foram convertidos em uma tabela com a ação antibacteriana dos extratos obtidos de todos os fungos da seleção, onde as linhagens fúngicas foram denominadas CDSA, demonstrado na Figura 4, onde é possível destacar alguns extratos que possuíram desempenhos satisfatórios com halos de inibição bacteriana maiores que $10 \mathrm{~mm}$, considerando o halo de inibição do controle positivo (Amoxicilina), que foi de $30 \mathrm{~mm}$, como o isolado CDSA71, que apresentou halo de inibição contra E. coli de $15 \mathrm{~mm}$, e os isolados CDSA04, CDSA08, CDSA15 e CDSA30, que apresentaram respectivamente $12 \mathrm{~mm}, 11 \mathrm{~mm}, 10 \mathrm{~mm}$ e $16 \mathrm{~mm}$ de halo de inibição. ${ }^{17}$ 
Figura 4 - Ação antibacteriana aos microrganismos teste dos extratos fúngicos obtidos após cultivo em meio semissólido ${ }^{\S}$

\begin{tabular}{|c|c|c|}
\hline \multirow{2}{*}{$\begin{array}{l}\text { ESPÉCIME } \\
\text { FÚNGICA }\end{array}$} & \multicolumn{2}{|c|}{ LINHAGENS BACTERIANAS } \\
\hline & Escherichia coli (ATCC 25922) & Staphylococcus aureus (ATCC 25923) \\
\hline CDSA01 & + & + \\
\hline CDSA02 & - & ++ \\
\hline CDSA03 & ++ & - \\
\hline CDSA04 & - & +++ \\
\hline CDSA05 & + & + \\
\hline CDSA06 & - & - \\
\hline CDSA07 & + & ++ \\
\hline CDSA08 & - & +++ \\
\hline CDSA09 & - & + \\
\hline CDSA 10 & + & + \\
\hline CDSA 11 & + & - \\
\hline CDSA12 & + & + \\
\hline CDSA13 & ++ & + \\
\hline CDSA 14 & ++ & - \\
\hline CDSA 15 & - & +++ \\
\hline CDSA16 & - & ++ \\
\hline CDSA17 & + & ++ \\
\hline CDSA 18 & + & + \\
\hline CDSA19 & - & - \\
\hline CDSA20 & - & - \\
\hline CDSA21 & + & + \\
\hline CDSA22 & + & + \\
\hline CDSA23 & - & ++ \\
\hline CDSA24 & - & + \\
\hline CDSA25 & - & - \\
\hline CDSA26 & - & - \\
\hline CDSA27 & + & + \\
\hline CDSA28 & - & - \\
\hline CDSA29 & + & - \\
\hline $\begin{array}{c}\text { CDSA30 (A } \\
\text { E B) }\end{array}$ & + & $++(\mathrm{A}),+++(\mathrm{B})$ \\
\hline CDSA31 & - & + \\
\hline CDSA32 & - & + \\
\hline CDSA33 & - & + \\
\hline CDSA34 & - & + \\
\hline
\end{tabular}

$\$+$ : Significa que a isolada fúngica em questão apresentou alguma atividade antibacteriana, que variou desde a inibição do crescimento bacteriano sobre o disco contendo o extrato do fungo, até a formação de halo antibacteriano cerca de 5 mm de diâmetro*.

++ : Significa que a linhagem fúngica apresentou atividade antibacteriana, formando um halo de atividade médio cerca de $10 \mathrm{~mm}$ de diâmetro*.

+++ Significa que a linhagem fúngica em questão apresentou atividade antibacteriana, formando um halo de atividade de cerca $15 \mathrm{~mm}$ de diâmetro*.

-: Significa que a linhagem fúngica em questão não apresentou nenhuma atividade antibacteriana.

A e B: O extrato obtido formou duas fases, denominadas A e B.

* Considerando o halo de atividade formado pelo controle usado, Amoxicilina $250 \mathrm{mg} / 2,5 \mathrm{ml}$, halo de atividade cerca de $30 \mathrm{~mm}$ de diâmetro. 


\begin{tabular}{|c|c|c|}
\hline CDSA35 & - & + \\
\hline CDSA36 & - & - \\
\hline CDSA37 & + & + \\
\hline CDSA38 & - & + \\
\hline CDSA39 & + & + \\
\hline CDSA40 & - & + \\
\hline CDSA41 & - & + \\
\hline CDSA42 & - & - \\
\hline CDSA43 & + & + \\
\hline CDSA44 & - & - \\
\hline CDSA45 & - & - \\
\hline CDSA46 & - & - \\
\hline CDSA47 & - & - \\
\hline CDSA48 & - & - \\
\hline CDSA49 & - & + \\
\hline CDSA50 & - & + \\
\hline CDSA51 & - & + \\
\hline CDSA52 & + & + \\
\hline CDSA53 & + & + \\
\hline CDSA54 & + & + \\
\hline CDSA55 & - & - \\
\hline CDSA56 & + & + \\
\hline CDSA57 & + & + \\
\hline CDSA58 & - & + \\
\hline CDSA59 & + & + \\
\hline CDSA60 & - & + \\
\hline CDSA61 & + & + \\
\hline CDSA62 & - & - \\
\hline CDSA63 & - & + \\
\hline CDSA64 & - & + \\
\hline CDSA65 & - & ++ \\
\hline CDSA66 & + & + \\
\hline CDSA67 & + & + \\
\hline CDSA68 & - & ++ \\
\hline CDSA69 & - & + \\
\hline CDSA70 & + & + \\
\hline CDSA71 & +++ & ++ \\
\hline CDSA72 & + & + \\
\hline
\end{tabular}

Fonte: os autores.

Nota-se na Figura 4 que os extratos avaliados nos testes antibiograma que apresentaram atividade satisfatória sobre a cepa de $S$. aureus apresentaram pouca ou nenhuma atividade sobre a cepa de E. coli, com exceção do isolado CDSA71 que apresentou maior atividade antibacteriana para E. coli. Isto pode ser atribuído ao fato de que os metabólitos produzidos pelos fungos com atividade 
antibiótica sejam mais eficazes contra bactérias Gram-positivas pelo fato de a sua parede celular ser mais transigente que a parede celular das bactérias Gram-negativas, que possuem uma membrana externa à parede celular que dificulta a ação de certos antibióticos. ${ }^{1} 8$

Hoje a Coleção de Fungos conta com 117 isolados, graças aos esforços do grupo da bioprospecção, há também pelo menos três linhas distintas de pesquisa, todas utilizando os fungos da seleção. É importante destacar que esta é a primeira Coleção de Fungos do Semiárido da UFCG, formando, assim, a primeira CCM da Instituição apenas com microrganismos do Bioma Caatinga.

\subsection{PURIFICAÇÃO PARCIAL DOS METABÓLITOS BIOATIVOS}

Diante dos resultados obtidos na bioprospecção, os isolados que apresentaram maior atividade contra os microrganismos teste utilizados foram selecionados para os testes de produção e purificação dos compostos. Dessa forma, de acordo com os resultados mostrados na Figura 4 foram selecionados seis isolados (CDSA01, CDSA07, CDSA30, CDSA59, CDSA70 e CDSA71), por apresentarem os resultados mais promissores nos testes antibiograma.

Esses isolados foram submetidos à fermentação líquida em meio contendo Extrato de Malte e Dextrose, e, após a etapa fermentativa, realizou-se a extração dos metabólitos bioativos com clorofórmio, por sua capacidade de extração comprovada na etapa anterior dos testes antibiograma. Os resultados métricos dos testes antibiograma foram convertidos na Figura 5, onde é possível observar que o extrato obtido do isolado CDSA30 no cultivo em meio líquido não formou duas fases como aconteceu no cultivo em meio semissólido e apresentou atividade mínima.

Figura 5 - Ação antibacteriana aos microrganismos teste dos extratos fúngicos obtidos após cultivo em meio líquido'

\begin{tabular}{|l|l|l|l|l|l|l|l|l|l|l|l|l|l|l|l|l|l|l|l|}
\hline $\begin{array}{l}\text { ESPECIME } \\
\text { FÚNGICA }\end{array}$ & \multicolumn{2}{l|}{ CDSA01 } & \multicolumn{2}{l|}{ CDSA07 } & \multicolumn{2}{l|}{ CDSA30 } & \multicolumn{2}{l|}{ CDSA59 } & \multicolumn{2}{l|}{ CDSA70 } & \multicolumn{2}{l|}{ CDSA71 } \\
\hline FASE & A & B & C & A & B & C & A & B & C & A & B & C & A & B & C & A & B & C \\
\hline E. coli & - & - & + & - & - & - & - & - & - & + & + & - & - & - & - & - & - & - \\
\hline S. aureuls & - & + & - & - & - & - & + & - & - & - & + & - & - & - & - & + & - & - \\
\hline
\end{tabular}

Fonte: os autores.

Conforme disposto na Figura 5, os resultados foram insatisfatórios para a continuidade das fermentações em meio líquido, uma vez que na fermentação em meio semissólido de aveia, os extratos obtidos apresentaram halos maiores que $10 \mathrm{~mm}$ para os isolados selecionados nessa etapa.

Segundo Gesheva, Ivanova e Gesheva, ${ }^{19}$ o método de cultivo de um fungo filamentoso influencia a produtividade de seus metabólitos secundários, bem como na produção de agentes antimicrobianos. Logo, nesse caso, a baixa atividade pode ter acontecido pela troca do meio de cultura,

+: Significa que a linhagem fúngica em questão apresentou alguma atividade antibacteriana, que variou desde a inibição do crescimento bacteriano sobre o disco contendo o extrato do fungo, até a formação de halo antibacteriano cerca de 5 mm de diâmetro.

-: Significa que a linhagem fúngica em questão não apresentou nenhuma atividade antibacteriana. 
o meio líquido pode não ter sido favorável à produção de compostos com atividade antibiótica, o tempo de incubação em meio líquido pode ter influenciado, já que em meio semissólido o fungo necessitava de mais tempo de incubação.

O cultivo em meio líquido foi uma tentativa de facilitar a etapa de purificação, pois seria mais fácil trabalhar com o extrato obtido em meio líquido, porém, como o cultivo em meio líquido diminuiu a atividade dos extratos, e no caso do isolado CDSA70 se extinguiu, decidiu-se, a partir desse ponto, conduzir os experimentos realizando a fermentação em meio semissólido de aveia apenas.

\subsection{INFLUÊNCIA DA TEMPERATURA NA PRODUÇÃO DE ANTIBIÓTICOS}

Para os testes de influência da temperatura na produção dos antibióticos, foram cultivados os isolados CDSA30 e CDSA71 em meio semissólido de aveia, por terem apresentado os melhores resultados nos testes antibiograma (Figura 4) contra as duas cepas bacterianas utilizadas. O experimento foi conduzido em cinco repetições $(n=5)$, seguido dos testes antibiograma dos extratos obtidos do cultivo em cada temperatura.

Os resultados mostraram que a uma temperatura de $45{ }^{\circ} \mathrm{C}$ houve uma maior produção de metabólitos secundários para os espécimes CDSA71 e CDSA30, capazes de inibir as duas espécies bacterianas, embora a temperatura de $37^{\circ} \mathrm{C}$ tenha sido utilizada durante todo o estudo, pois é a temperatura média ambiente utilizada antes desse tipo de teste. A temperatura de $28{ }^{\circ} \mathrm{C}$ também gerou extratos com bons halos de inibição, conforme demonstram as Figuras 7 e 8, o que indica que esses dois isolados são capazes de produzir compostos antibióticos em escalas diferentes de temperatura, mas há maior produção à temperatura de $45^{\circ} \mathrm{C}$. 
Figura 6 - Atividade antimicrobiana média $(\mathrm{mm})$ de extratos fúngicos à E. coli submetidos a diferentes temperaturas de incubação"

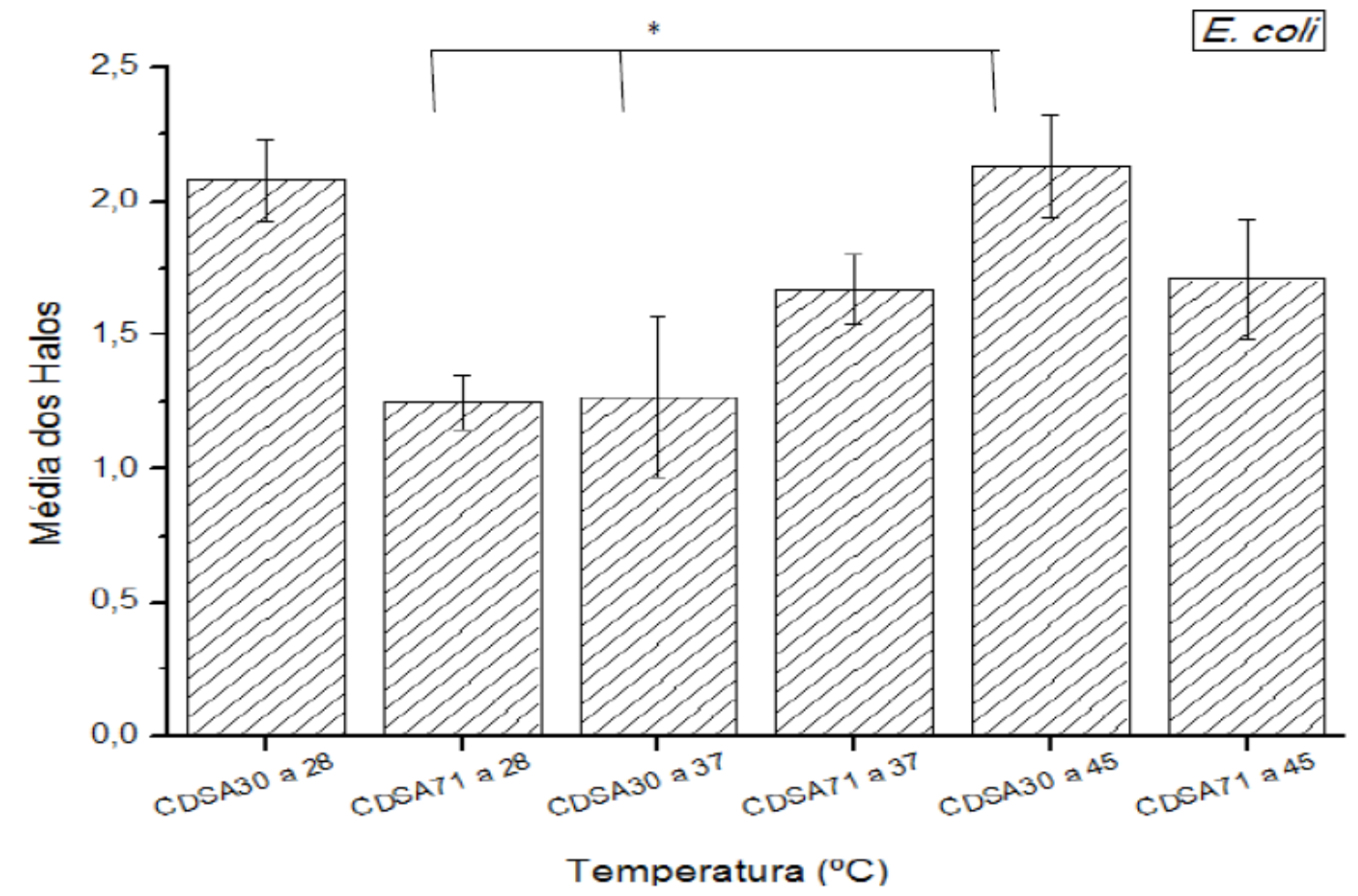

Fonte: os autores.

Figura 7 - Atividade antimicrobiana média (mm) de extratos fúngicos à S. aureus, submetidos a diferentes temperaturas de incubação.

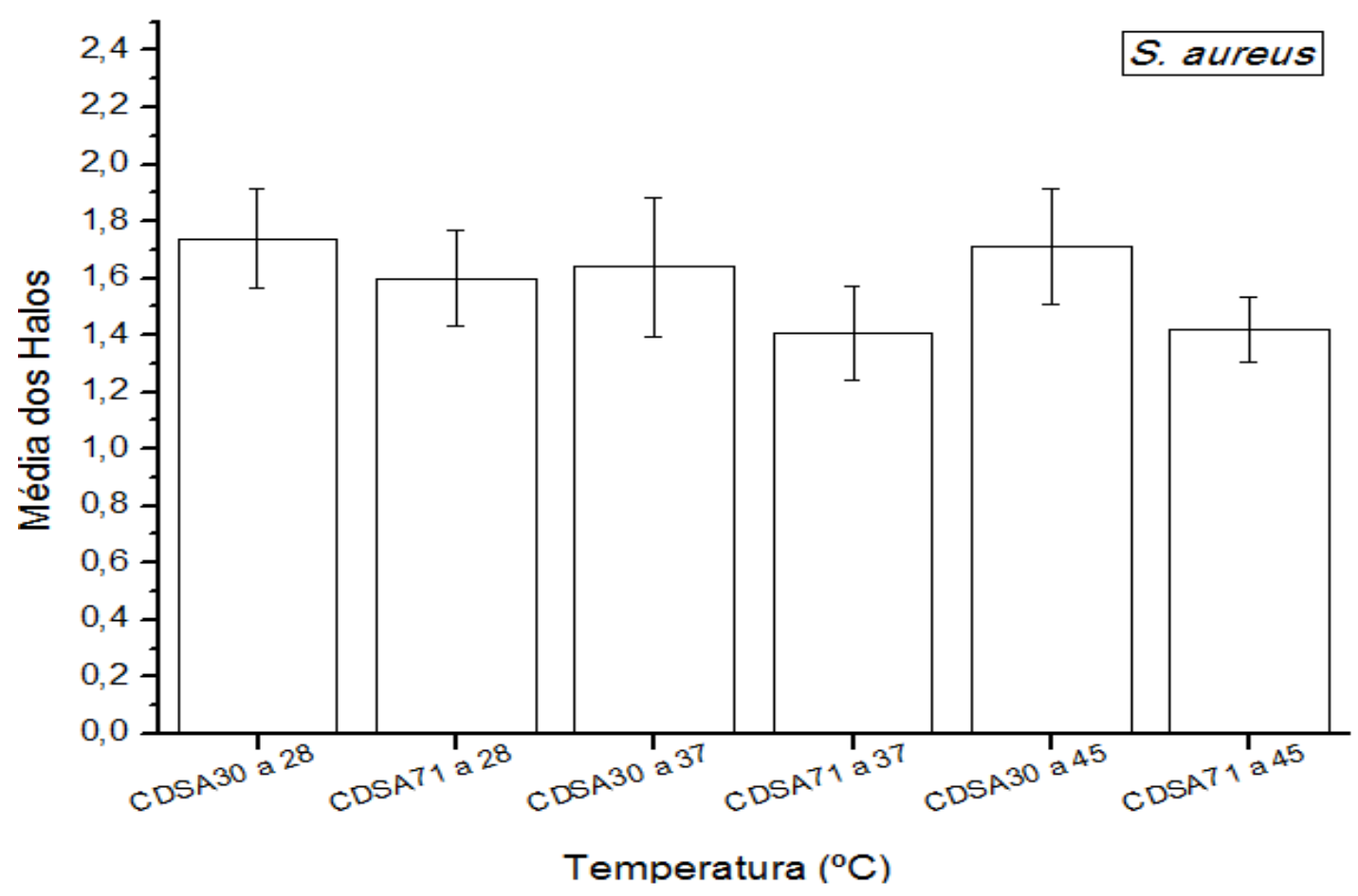

Fonte: os autores.

" Resultados significativos, considerando $\mathrm{p}<0,05$. 


\subsection{PURIFICAÇÃO DOS EXTRATOS OBTIDOS VIA FERMENTAÇÃO SEMISSÓLIDA}

O resultado da CLAE-FR na forma de operação analítica mostrou que os compostos obtidos dos espécimes CDSA71 e CDSA30 apresentaram seis picos, ou seja, seis possíveis compostos diferentes responsáveis pela atividade antimicrobiana, observados nos cromatogramas das Figuras 8 e 9.

Figura 8 - Cromatograma em coluna analítica do extrato obtido do espécime CDSA71 ${ }^{\dagger}$

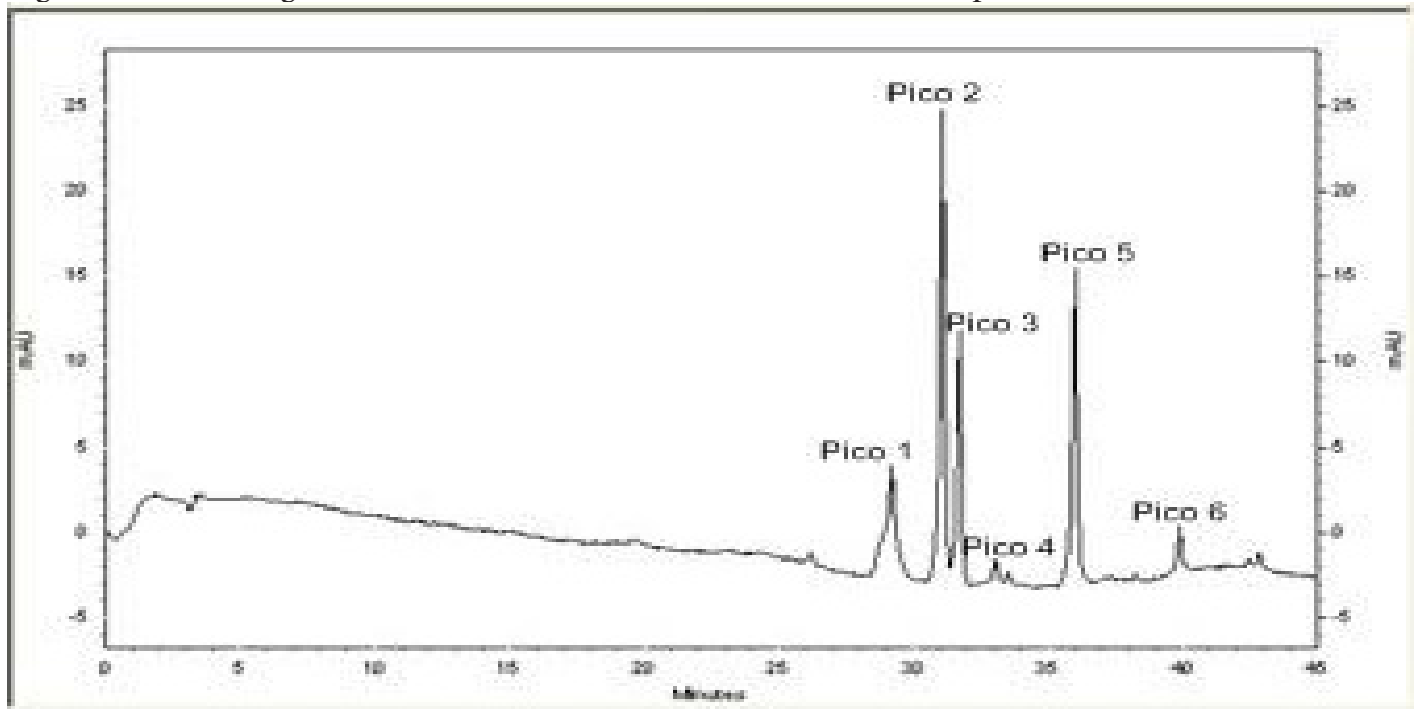

Fonte: os autores.

Figura 9 - Cromatograma em coluna analítica do extrato obtido do espécime CDSA $30^{\text {tो }}$

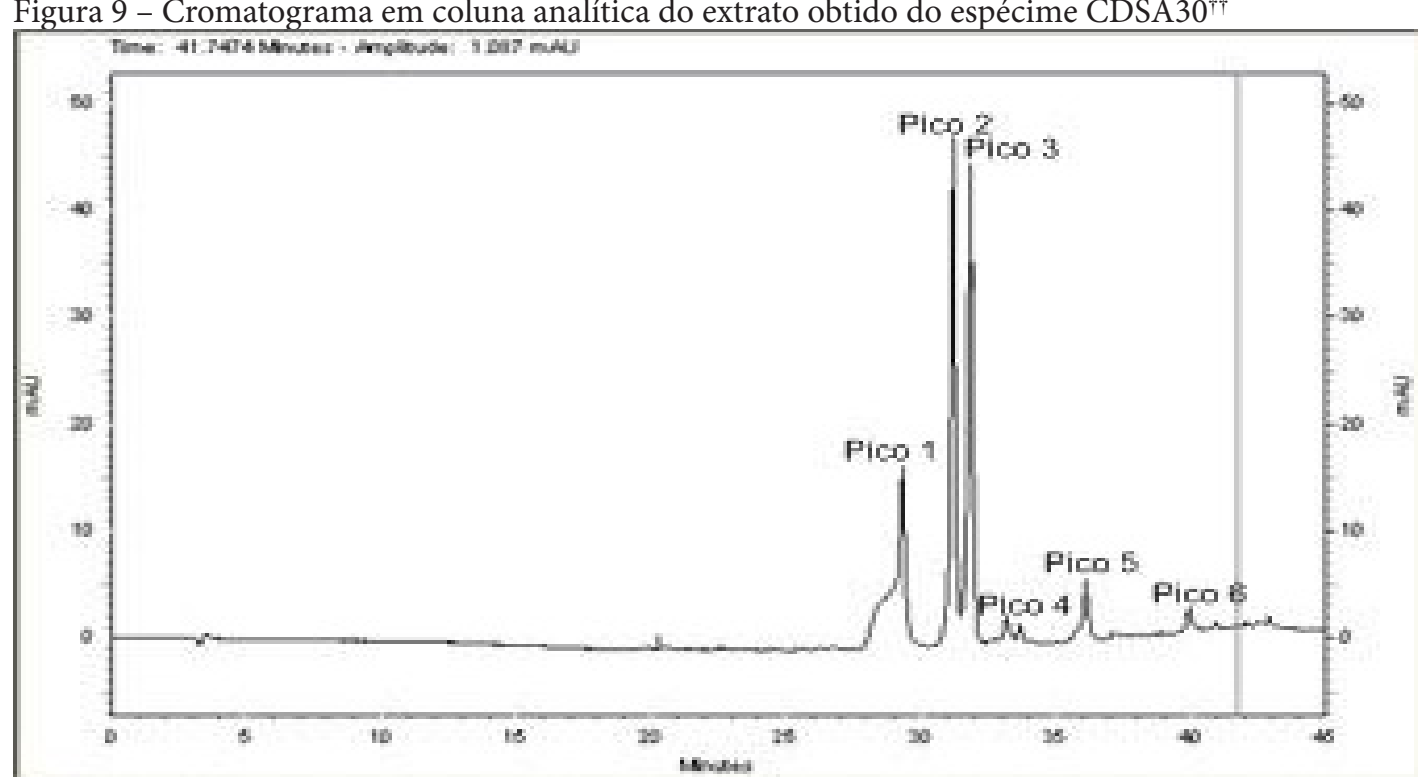

Fonte: os autores.

\footnotetext{
${ }^{\dagger \dagger}$ Análise realizada em coluna ShimPak - Shimadzu, a um fluxo de $1 \mathrm{~mL} / \mathrm{min}$, com gradiente crescente de metanol em $30 \mathrm{~min}$, de 5 a 35 min, de 5 a $95 \%$ de metanol, respectivamente.
} 
Os cromatogramas dos dois isolados possuem alta similaridade, o que confirma os testes prévios realizados, em que ambos apresentam alta atividade contra as duas cepas bacterianas testadas neste trabalho. Esses isolados possuem compostos antimicrobianos com atividade semelhante, conforme visto na Figura 4.

A Figura 10 mostra o resultado do teste antibiograma do extrato purificado obtido do isolado CDSA71 após fermentação em meio semissólido de aveia, o resultado mostra que apenas dois dos seis compostos encontrados apresentaram atividade mínima, se comparados ao efeito sinérgico destes no extrato total.

\begin{tabular}{|c|c|c|}
\hline $\begin{array}{c}\text { CDSA } \\
71\end{array}$ & $\begin{array}{c}\text { E. coli (ATCC } \\
\text { 25922) }\end{array}$ & $\begin{array}{c}\text { S. aureaus (ATCC } \\
25923 \text { ) }\end{array}$ \\
\hline Pico 1 & - & - \\
\hline Pico 2 & - & - \\
\hline Pico 3 & - & - \\
\hline Pico 4 & - & - \\
\hline Pico 5 & + & + \\
\hline Pico 6 & + & + \\
\hline
\end{tabular}

Após a purificação, conseguiu-se testar apenas o material obtido do CDSA71 em que os picos 5 e 6 foram favoráveis à inibição parcial do crescimento bacteriano, conforme visto na Figura 10, gerando halos de inibição de aproximadamente $2 \mathrm{~mm}$. Os picos 1, 2, 3 e 4 não apresentaram atividade à nenhuma cepa bacteriana, o que é possível afirmar que o efeito sinérgico dos compostos contidos no extrato pode apresentar maior atividade antibacteriana, ou a quantidade de composto isolado pode não ter sido suficiente para causar um efeito de inibição maior.

Oliveira, ${ }^{20}$ ao analisar fungos endofíticos de Piper hispidum na Amazônia, conseguiu purificar e caracterizar compostos semelhantes aos antibióticos comerciais amoxicilina e cefaloxina por meio da sobreposição dos cromatogramas obtidos com os cromatogramas dos antibióticos comerciais, ele observou que para alguns compostos isolados o efeito sinérgico do extrato foi maior do que o efeito da substância isolada presente no extrato.

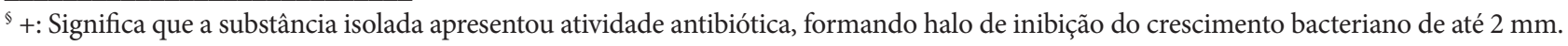
-: Significa que a substância isolada não apresentou atividade antibiótica.
} 


\subsection{IDENTIFICAÇÃO DOS ISOLADOS FÚNGICOS}

Os fungos foram identificados segundo a comparação das imagens obtidas por microscópio óptico e as imagens encontradas em literatura especializada. Os resultados mostraram que tanto o isolado CDSA71 quanto o CDSA30 são espécies do gênero Aspergillus, conforme Figuras 11 e 12, comum nessa região, com frequência significativa no solo e no rr. $^{21}$ Foi realizada a observação das lâminas em microscópio óptico com aumento de 40 vezes. As características macro e microscópias, bem como as estruturas reprodutivas (conidióforos - hifa especializada que origina os conídios) das culturas em meio BDA, foram comparadas com as descritas e ilustradas por Barnett e Hunter, ${ }^{22}$ Vidotto $^{23}$ e Quadros. $^{24}$

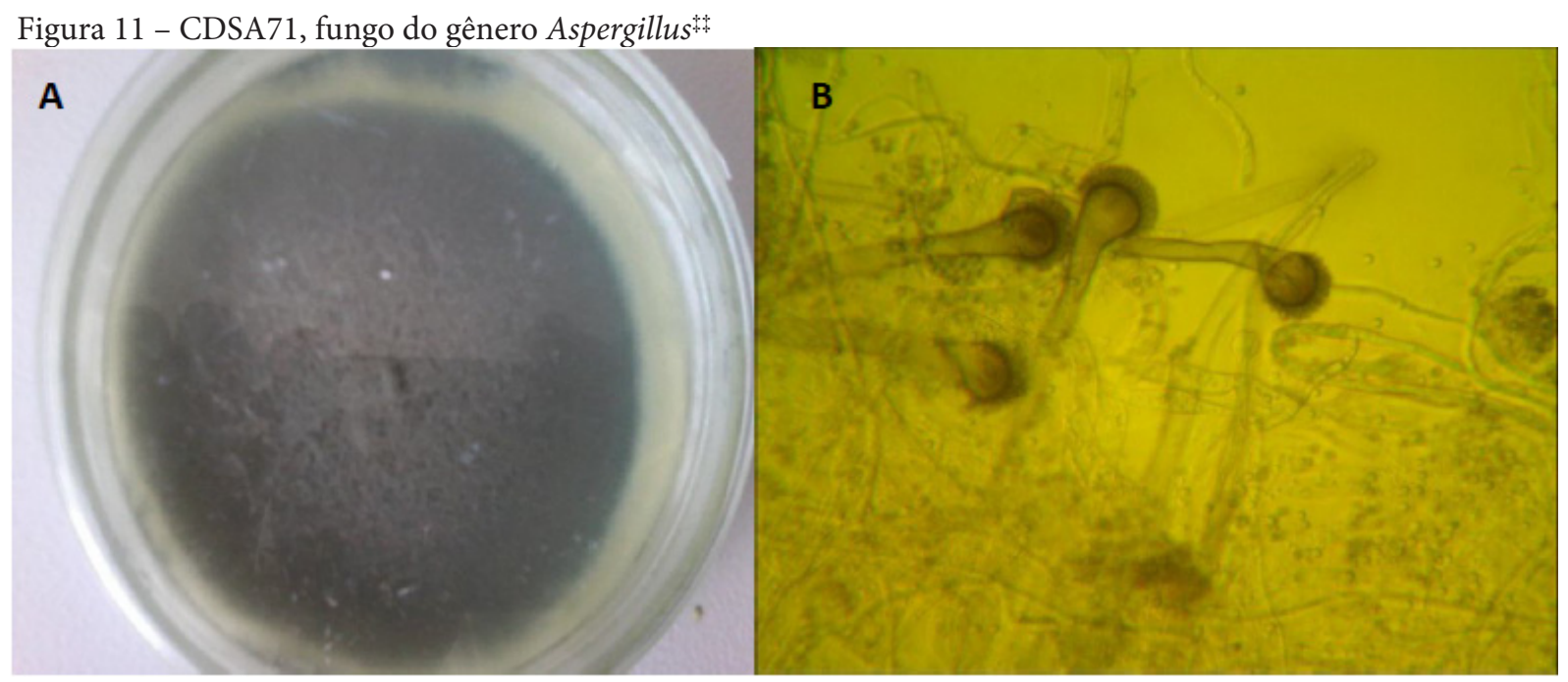

Fonte: os autores.

Figura 12 - CDSA30, fungo do gênero Aspergillus ${ }^{\star *}$

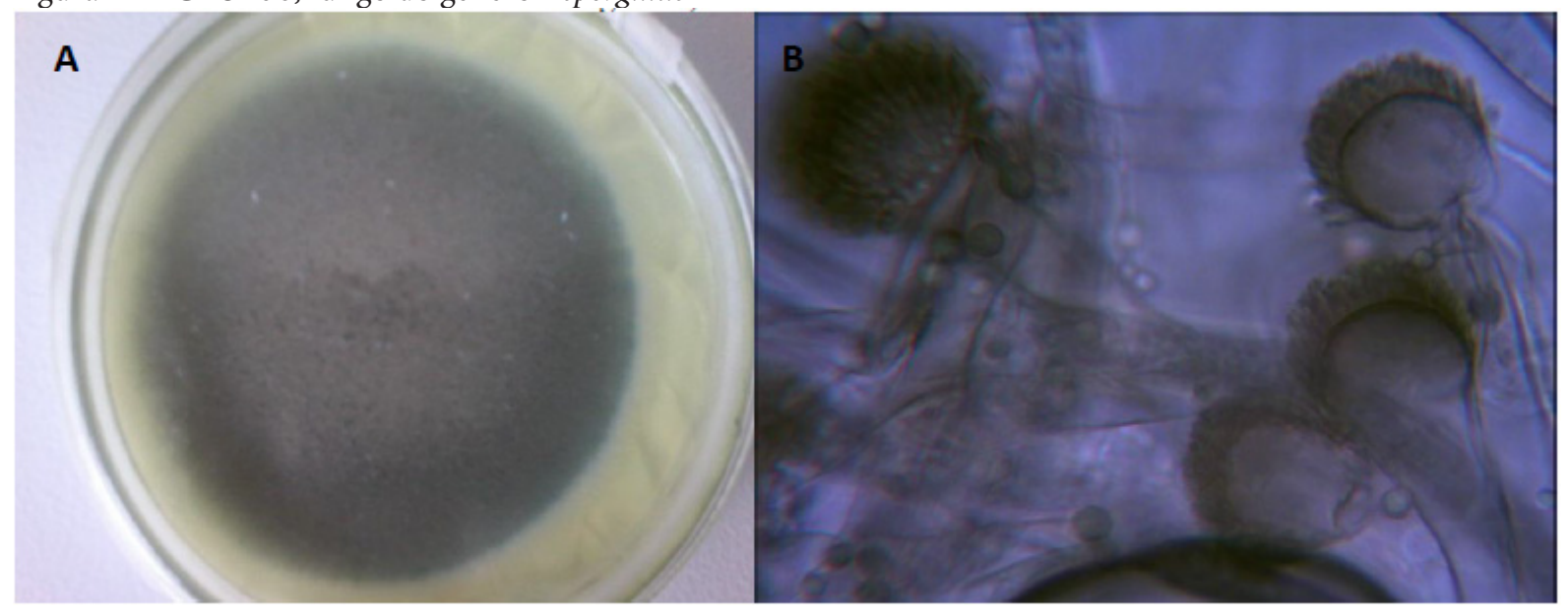

Fonte: os autores.

\footnotetext{
${ }^{\ddagger} \mathrm{Na}$ imagem A, colônia após sete dias de crescimento, na imagem B, conídios e conidióforos.
} 
Características Macroscópicas: os isolados apresentaram, enquanto colônias jovens, o micélio branco, com colônias filamentosas e com aspecto aveludado. Durante seu crescimento foram assumindo a cor verde, com bordas brancas e reverso amarelado.

Características Microscópicas: os dois isolados apresentam características semelhantes, possuem hifas septadas e hialinas. Apresentam conidióforos que se desenvolvem rapidamente. Os microconídeos (blastoconídeos) são produzidos em série pelas fiálides; ${ }^{5}$ essa produção de blastoconídeos por um único conidióforo forma extremidades conidiais volumosas, apresentando-se na forma de franja ou achatada.

Com essa informação sobre a identificação dos fungos, pode-se afirmar que apesar de os isolados serem do mesmo gênero, foi possível observar que estes produziram metabólitos secundários em quantidades diferenciadas quando cultivados em meio de aveia, o que induz ao raciocínio de que apesar de serem do mesmo gênero e com características morfológicas bastante semelhantes podemos ter duas espécies diferentes do gênero Aspergillus, fato comum observado por Pereira et al., ${ }^{21}$ que ao isolarem fungos da região da Borborema e do Cariri paraibano para identificá-los e quantificá-los, catalogaram quatro espécies desse gênero, o A. niger, A. flavus, A.terreus e A.ochraceos.

As perspectivas futuras são de continuar a purificação dos extratos obtidos dos espécimes que apresentaram atividade antibiótica, buscar novas formas de obtenção dos extratos de forma que facilite a etapa de purificação. Posteriormente, realizar os testes para descobrir que substâncias estão sendo responsáveis pelo efeito antibiótico, e como elas se comportam em relação ao efeito apresentado nos testes antibiograma; conseguinte, pretende-se também verificar a dose-dependência dessas substâncias.

\section{CONCLUSÃO}

Fungos da Caatinga sob condições favoráveis de cultivo produzem antibióticos contra bactérias Gram positivas e/ou Gram negativas. Para atingir essa produtividade, foi necessário o cultivo em meio de aveia, e a temperatura de cultivo que proporcionou um maior rendimento na produção de extratos com atividade antibiótica foi de $45^{\circ} \mathrm{C}$. A purificação dos metabólitos secundários via CLAEFR resultou em moléculas isoladas com atividade antibacteriana, e a identificação por microcultivo mostrou que os fungos produtores de antibióticos que tiverem seus compostos purificados são do gênero Aspergillus.

\section{REFERÊNCIAS}

1. Crag GM, Newman DJ. Biodiversity: a counting source of novel drug leads. Pur and Appl Chem. 2005; 77(1):7-24. 
2. Jang KW, Nam SJ, Locke JB, Kauffman CA, Beatty DS, Paul AL, et al. Anthracimycin, a Potent Anthrax Antibiotic from a Marine-Derived Actinomycete. Ang Chem Intern Ed. 2013; 52:78227824.

3. Strobel G, Daisy B. Bioprospecting for Microbial Endophytes and their natural productis. Microb Molec Biol Rev. 2003; 67:491-502.

4. Lopes FC. Produção e Análise de Metabólitos Secundários de Fungos Filamentosos [dissertação]. Porto Alegre: Universidade Federal do Rio Grande do Sul; 2011.

5. Santos SN. Bioprospecção de biomoléculas isoladas de fungos endofíticos de Cobretum leprosum do bioma Caatinga [tese]. Piracicaba: Escola Superior de Agricultura Luiz de Queiroz; 2012.

6. Campos FF. Isolamento e identificação de substâncias bioativas produzidas por fungos endofíticos associados à Piptadenia adiantoides (Fabaceae) [tese]. Minas Gerais: Universidade Federal de Minas Gerais; 2009.

7. Momesso LS. Estudo químico-biológico dos fungos endofíticos Cladosporium Sphaerospermum, Pestalotiopsis guepini e Chaetomium globosum [tese]. Ribeirão Preto: Faculdade de Ciências Farmacêuticas de Ribeirão Preto; 2008.

8. Silva JMC, Tabarelli M, Fonseca MT, Lins LV. Biodiversidade da Caatinga: áreas e ações prioritárias para a conservação. Brasília: Ministério do Meio Ambiente: SBF; 2002.

9. Prado D. As caatingas da América do Sul. In: Leal IR, Tabarelli M, Silva JMC, editors. Ecologia e conservação da Caatinga. Recife: Universitária; 2003.

10. Farmacopéia Brasileira. 4a. ed. São Paulo: Ind. Gráfica Siqueira; 1988

11. Viali L. Testes Não Paramétricos [Internet]. Porto Alegre: Departamento de Matemática da Universidade Federal do Rio Grande do Sul. [acesso em 2014 jun 10]. Disponível em: http://www. mat.ufrgs.br/ viali/estatistica/mat2282/material/laminaspi/Mat2282_2_Ind.pdf

12. Agência Nacional de Vigilância Sanitária. Detecção e Identificação de Fungos de Importância Médica. Brasília; 2004.

13. Calvo AM, Wilson RA, Bok JW, Keller NP. Relationship between secondary metabolismand fungal development. Microb and Molec Biol Rev. 2002; 66(3):447-459.

14. Okafor N. Modern industrial microbiology and biotechnology. Sci Publ. Enfield; 2007.

15. Pelczar MJ, Chan ECS, Krieg NR. Microbiologia: conceitos e aplicações. São Paulo: Pearson Makron Books; 1997.

16. Bachiega G L, Vilegas W, Ujikawa K. Antibiótico antifúngico produzido por um estreptomiceto da região de Araraquara. Rev Ciênc Farm Bás Aplic, 2005; 26(1):29-37. 
17. Silva FD, Queiroz JC. Bioprospeccção de antibióticos produzidos por fungos da Caatinga. In: IX Congresso de Iniciação Científica da UFCG, 2012; Campina Grande; 2012.

18. Tortora GJ, Funke BR, Case CL. Microbiologia. 10a. ed. Porto Alegre: Artmed; 2012.

19. Gesheva V, Ivanova V, Gesheva R. Effects of nutrients on the production of AK-111-81 macrolide antibiotic by Streptomyces hygroscopicus. Microbiological Research. [S.1.]: Elsevier GmbH., 2005; 160:243-248.

20. Oliveira RL. Avaliação do Potencial Biotecnológico de Fungos Endofíticos de Piper hispidum [dissertação]. Manaus: Universidade do Estado do Amazonas; 2010.

21. Pereira FO, Lima EO, Figueiredo KRL, Brito LL, Meira AS. Microbiota fúngica do solo e ar atmosférico na região da Borborema, estado da Paraíba, Brasil. Rev Bras Anál Clín. 2010; 42(2):123126.

22. Barnett HL, Hunter BB. Illustrated genera of imperfect fungi. 4a. ed. The American Phytopathological Society, St. Paul: Minnesota; 1998.

23. Vidotto V. Manual de micologia médica. 1a. ed. Ribeirão Preto: Tecmedd; 2004.

24. Quadros M. Qualidade do ar em ambientes internos hospitalares: parâmetros físico-químicos e microbiológicos [dissertação]. Florianópolis: Universidade Federal de Santa Catarina; 2008.

25. Bisognin RP. Análise do Potencial Microbiano de uma Biopilha na Biorremediação de solos contaminados por Hidrocarbonetos [dissertação]. Santa Cruz do Sul: Universidade de Santa Cruz do Sul; 2012. 